\title{
Colon specific delivery of budesonide based on triple coated pellets: In vitrolin vivo evaluation
}

\author{
JALEH VARSHOSAZ ${ }^{1 *}$ \\ JABER EMAMI ${ }^{1}$ \\ NASER TAVAKOLI ${ }^{1}$ \\ MOHSEN MINAIYAN ${ }^{2}$ \\ NAKISA RAHMANI ${ }^{1}$ \\ FARID DORKOOSH ${ }^{3}$ \\ PARVIN MAHZOUNI ${ }^{4}$ \\ ${ }^{1}$ Department of Pharmaceutics, Faculty \\ of Pharmacy and Novel Drug Delivery \\ Systems Research Center, Isfahan \\ University of Medical Sciences \\ Isfahan, Iran \\ 2 Department of Pharmacology, Faculty \\ of Pharmacy and Isfahan Pharmaceutical \\ Sciences Research Center, Isfahan \\ University of Medical Sciences \\ Isfahan, Iran
}

${ }^{3}$ Department of Pharmaceutics, Faculty of Pharmacy, Tehran University of Medical Sciences, Tehran, Iran

${ }^{4}$ Department of Clinical Pathology, Faculty of Medicine, Isfahan University of Medical Sciences, Isfahan, Iran

\begin{abstract}
Three layered pellets of budesonide were prepared for colon delivery by the extrusion-spheronization method. The coatings consisted of hydroxypropylmethyl cellulose (HPMC) (as barrier layer), Eudragit E (as rate controlling layer) and hydroxypropylmethyl cellulose acetate succinate (HPMC AS) (as enteric layer). The rate controlling layer was further modified using various pore formers. Dissolution studies were carried out at $\mathrm{pH}$ 1.2, 7.4 and 6.8. Pellet core composition and type and level of pore former affected the drug release from pellets. Pellets containing $20 \%(\mathrm{~m} / \mathrm{m})$ citric acid in the cores coated with HPMC at a coating level of $6 \%(\mathrm{~m} / \mathrm{m})$, Eudragit E containing Avicel RC 581 (30\%) as pore former at a coating level of $30 \%(\mathrm{~m} / \mathrm{m})$ and HPMC AS at a coating level of $15 \%(\mathrm{~m} / \mathrm{m})$ had the best release profiles. These pellets showed promising results in alleviating the conditions of an experimental model of colitis induced by trinitrobenzenesulfonic acid in rats.
\end{abstract}

Keywords: colon delivery, three layered pellets, Eudragit E, budesonide, HPMC AS, HPMC

\footnotetext{
* Correspondence; e-mail: varshosaz@pharm.mui.ac.ir
} 
Budesonide (BUD) is a locally acting corticosteroid with high affinity for glucocorticoid receptors. It offers several therapeutic advantages over old steroids such as hydrocortisone, prednisolone and dexamethasone. The advantages that made BUD a standard drug for the localized treatment of inflammatory bowel disease include: negligible oral bioavailabilability, rapid clearance and no active metabolites $(1,2)$. These advantages made this drug a standard drug for the localized treatment of inflammatory bowel disease $(1,2)$. BUD is currently marketed in several different commercial forms, as oral controlled-ileal-release formulations targeted at the distal ileum and right-sided colonic region in Crohn's disease, or as enema for the treatment of left-sided ulcerative colitis (UC) (3). However, no BUD formulation is available for the oral treatment of UC (3). It seems that rapid presystemic elimination of BUD in hepatocytes and in epithelial cells of the small intestine wall prevents sufficient bioavailability in colonic mucosa $(4,5)$.

There is a growing interest in multiparticulate modified release drug delivery systems especially for site specific targeting within the gastrointestinal tract. Asghar and Chandran (6) provided a multiparticular formulation for colon delivery of drugs with more uniform in vivo dissolution performance compared to single unit dosage forms. It resulted in more uniform inter-individual bioavailability and clinical effects. Therefore several reports of successful colon targeting of BUD based on multiparticulate systems including microparticles (7) and nanoparticles (8) are available. However, these systems are comparatively complex and their large-scale manufacturing requires many skills and technological development. Among the different types of multiple-unit dosage forms, pellets still appear as one of the most attractive dosage forms from the economic, process development and scale-up points of view. Pellets combine the advantages of multiparticulate dosage forms with the established manufacturing techniques of pelletization, which are easier and have fewer limitations compared to microparticles and nanoparticles. The present work is aimed at enhancing the effectiveness of BUD in the treatment of UC. In this regards, triple coated pellets were investigated as a potential delivery system of BUD to the large intestine. The triple-coated pellet formulation consisted of BUD along with conventional excipients and various amounts of citric acid coated with a barrier layer of hydroxypropylmethyl cellulose (HPMC), a rate controlling layer of Eudragit $\mathrm{E}$ and an enteric coat of hydroxypropylmethyl cellulose acetate succinate (HPMC AS). Different formulation variables, including different pellet core composition and Eudragit E layer composition, were studied and optimized to achieve the desired release profile and in vivo performance.

\section{EXPERIMENTAL}

\section{Materials}

Budesonide was obtained as a gift sample from Astra Zeneca (UK), Eudragit E-100 was kindly donated by Rohm Pharma (Germany), the microcrystalline cellulose grades (Avicel PH 101 and Avicel RC581) were obtained from FMC (Ireland), hydroxypropylmethyl cellulose acetate succinate (HPMC AS), hydroxypropylmethyl cellulose (HPMC) USP Substitution Type 2208 with $15000 \mathrm{mPa}$ s viscosity and HPMC USP Substitution Type 2910 with $6 \mathrm{mPa}$ s viscosity were obtained from Shin-Etsu Chemical Co. (Japan), lactose 
monohydrate 200 from Meggle (Germany), citric acid from Kimya Gharb Gostar (Iran), talc and triethyl citrate (TEC) from Kirsch Pharma (Germany) and trinitrobenzenesulfonic acid (TNBS) from Sigma Chemicals (USA). All other solvents and chemicals used were of analytical grade.

\section{Animals}

Normal healthy male Wistar rats (Faculty of Pharmacy of Isfahan University of Medical Sciences, Iran) weighing 180-220 g, were used. The animals were housed under environmentally controlled conditions $\left(22 \pm 2{ }^{\circ} \mathrm{C}, 12\right.$-h light-dark cycle), with free access to water and a standard chow pellet diet. The rats were allowed to acclimatize for 1 week before experiment. They were fasted for $24 \mathrm{~h}$ before induction of colitis. The animal study was approved by the ethical committee of the Isfahan University of Medical Sciences, Isfahan, Iran.

\section{Preparation of pellet cores}

Pellet cores were prepared by the extrusion-spheronization method (extruder, Model 20, fitted with a spheronizer, model 250, Caleva, UK). Four pellet core formulations were designed with different compositions, as given in Table I. Distilled water was used as granulating agent. The obtained pellets were dried for $24 \mathrm{~h}$ at room temperature. The pellets in the size range of $840-1000 \mu \mathrm{m}$ were used in subsequent coatings.

\section{Coating of pellet cores}

Pellet cores were coated in a fluidized bed coating apparatus (VECTOR Corporation, USA) with three successive layers: an inner HPMC layer, an outer Eudragit E and an enteric-coating layer (HPMC AS). The HPMC layer consisted of HPMC $(10 \%, m / m)$, TEC $(1 \%, m / m)$, talc $(2.5 \%, m / m)$ and water $(86.5 \%, \mathrm{~m} / \mathrm{m})$. The coating level of HPMC layer was $6 \%, m / m$. The Eudragit E layer consisted of Eudragit E-100 $(12 \%, m / m)$, TEC $(2.4 \%, \mathrm{~m} / \mathrm{m})$ and talc $(1.2 \%, \mathrm{~m} / \mathrm{m})$ in an ethyl alcohol/water mixture $(60: 40, \mathrm{~V} / \mathrm{V})$. In addition, some preparations contained lactose 200, HPMC 15000 or Avicel RC581 as pore former (Table II). The two-layer coated pellets were subsequently coated with HPMC AS to achieve a mass gain of 12 to $20 \%(\mathrm{~m} / \mathrm{m})$ and obtain complete multi-layer coated pellets (Fig. 1). The coating suspension used was HPMC AS $(7 \%, m / m)$, TEC $(1.96 \%, m / m)$, talc $(2.1 \%, \mathrm{~m} / \mathrm{m})$, sodium lauryl sulphate $(0.21 \%, \mathrm{~m} / \mathrm{m})$ and water $(88.73 \%, \mathrm{~m} / \mathrm{m})$. The process parameters are shown in Table III.

Table I. Compositions of investigated pellet cores

\begin{tabular}{lcccc}
\hline & \multicolumn{4}{c}{ Formulation number } \\
\cline { 2 - 5 } Component (\%) & F1 & F2 & F3 & F4 \\
\hline Budesonide & 1.5 & 1.5 & 1.5 & 1.5 \\
Avicel PH 101 & 6.0 & 6.0 & 6.0 & 6.0 \\
Avicel RC581 & 24.0 & 24.0 & 24.0 & 24.0 \\
Citric acid & 0 & 5.0 & 10.0 & 20.0 \\
Lactose 200 & 68.5 & 63.5 & 58.5 & 48.5 \\
\hline
\end{tabular}




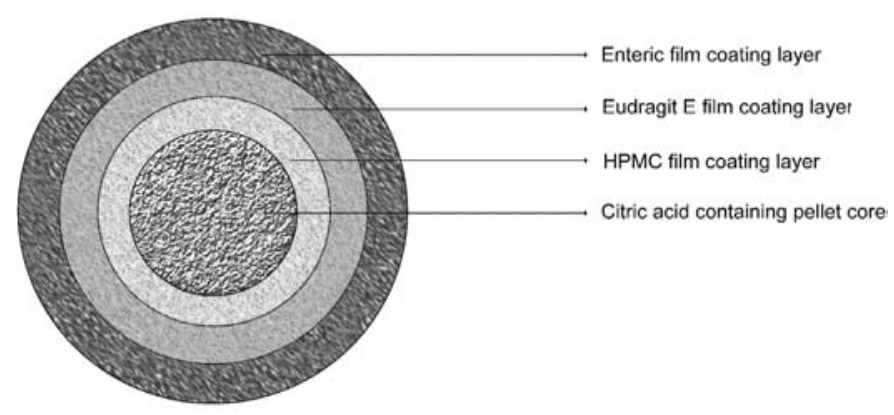

Fig. 1. Schematic presentation of the multi-layer film coated pellet of budesonide.

Table II. Formulation variables of Eudragit E layer

\begin{tabular}{lcccccc}
\hline \multirow{2}{*}{ Coating component } & \multicolumn{7}{c}{ Formulation code } \\
\cline { 2 - 7 } & LE1 & LE2 & LE3 & LE4 & LE5 & LE6 \\
\hline Eudragit E $(\%, m / m)$ & 10 & 10 & 10 & 10 & 10 & 10 \\
Talc $(\%, m / m$, of Eudragit E) & 12 & 12 & 12 & 12 & 12 & 12 \\
TEC $(\%, m / m$, of Eudragit E) & 24 & 24 & 24 & 24 & 24 & 24 \\
HPMC $15000(\%, m / m$, of Eudragit E) & - & 30 & 40 & 50 & - & - \\
Lactose 200 $(\%, m / m$, of Eudragit E) & - & - & - & - & 30 & - \\
Avicel RC581 $(\%, m / m$, of Eudragit E) & - & - & - & - & - & 30 \\
Mass gain $(\%, m / m)$ & 30 & 30 & 30 & 30 & 30 & 30 \\
\hline
\end{tabular}

HPMC - hydroxypropylmethyl cellulose

TEC - triethyl citrate

\section{Budesonide release studies}

The dissolution test of developed formulations was conducted in a USP paddle apparatus (9) at $50 \mathrm{rpm}$ at $37 \pm 0.5^{\circ} \mathrm{C}$. Drug release was measured from an accurately weighed amount of pellets, equivalent to $3 \mathrm{mg}$ of BUD. The influence of pellet core composition and Eudragit E layer composition on BUD release was evaluated in phosphate buffer (PBS) ( $\mathrm{pH} 6.8,250 \mathrm{~mL}$ ). Acid-resistance of the pellets was tested using $250 \mathrm{~mL}$ $\mathrm{HCl} 0.1 \mathrm{~mol} \mathrm{~L}^{-1}$ for $2 \mathrm{~h}$. For the optimized formulation, measurement of BUD release was carried out as a function of time at various $\mathrm{pH}$, which were selected to simulate $\mathrm{pH}$ conditions at different locations of GIT. The media consisted of $250 \mathrm{~mL}$ of $\mathrm{HCl} 0.1 \mathrm{~mol} \mathrm{~L}^{-1}$ for $2 \mathrm{~h}$, PBS (pH 7.4) for $4 \mathrm{~h}$ and PBS ( $\mathrm{pH} \mathrm{6.8)} \mathrm{for} 18 \mathrm{~h}$. In all drug release studies, $0.5 \%$ $(m / V)$ of SLS (9) was added to each dissolution medium to maintain sink conditions. The samples were withdrawn at various time intervals and replaced with an equivalent amount of fresh medium. Dissolution samples were filtered through a $0.45-\mu \mathrm{m}$ filter and analyzed using a validated HPLC method (10). 
J. Varshosaz et al.: Colon specific delivery of budesonide based on triple coated pellets: In vitro/in vivo evaluation, Acta Pharm. 62 (2012) 341-356.

Table III. Operating conditions for the coating experiments

\begin{tabular}{lccc}
\hline Operating condition & $\begin{array}{c}\text { Barrier coating } \\
\text { with HPMC }\end{array}$ & $\begin{array}{c}\text { Acid sensitive coating } \\
\text { with Eudragit E }\end{array}$ & $\begin{array}{c}\text { Enteric coating } \\
\text { with HPMC AS }\end{array}$ \\
\hline Before coating preheating to $\left({ }^{\circ} \mathrm{C}\right)$ & - & - & - \\
Coating nozzle diameter $(\mathrm{mm})$ & 1 & 1 & 1 \\
Spraying rate $\left.(\mathrm{g} \mathrm{min})^{-1}\right)$ & 0.4 & 2 & 1 \\
Inlet air temperature $\left({ }^{\circ} \mathrm{C}\right)$ & $70-72$ & $30-32$ & $30-32$ \\
Outlet air temperature $\left({ }^{\circ} \mathrm{C}\right)$ & $56-58$ & $25-28$ & $23-25$ \\
Curing in fluid bed & - & 30 min at $35{ }^{\circ} \mathrm{C}$ & 30 min at $60{ }^{\circ} \mathrm{C}$ \\
On trays & $24 \mathrm{~h}$ at room & - & - \\
\hline
\end{tabular}

\section{Citric acid release study}

Citric acid release study from Eudragit E coated pellets was carried out in a USP paddle apparatus (9). The paddle rotation speed was set at $50 \mathrm{rpm}$ and the dissolution medium was $250 \mathrm{~mL}$ of PBS ( $\mathrm{pH}$ 6.8). For each determination, three pellet samples were analyzed over 12 hours. The percent of released citric acid from the pellets was calculated from the actual citric acid content of each sample as a function of dissolution time and analyzed using a validated HPLC method (11).

\section{Stability studies}

Optimized formulation of BUD was subjected to accelerated stability studies to assess its stability with respect to physical appearance, drug content and drug release characteristics after storing under stress conditions of $40{ }^{\circ} \mathrm{C} / 75 \% \mathrm{RH}$ for 3 months in sealed glass vials.

\section{Reproducibility study}

Reproducibility of the coating procedures was confirmed by preparing three repeated batches of optimized formulation on three different occasions. Drug release of prepared batches was monitored and their release profiles were compared.

\section{Drug release kinetics}

The rate and mechanism of drug release was analyzed by fitting the dissolution data into several mathematical models, including zero-order, first-order, Higuchi and Hixson-Crowell equations (12-14). Dissolution profiles were compared by calculating the similarity factor. Similarity factor $\left(f_{2}\right)$ is a logarithmic transformation of the sum-squared error. If $f_{2}$ value is between 50 and 100, the two dissolution profiles are considered to be similar (15). 
In vivo studies

Induction of experimental colitis. - In vivo studies were performed according to Morris et al. (16) with some modifications. Colitis was induced under light ether anaesthesia by intracolonic administration of $0.5 \mathrm{~mL}$ ethanol $(40 \%, V / V)$ containing $20 \mathrm{mg}$ trinitrobenzenesulfonic acid using a flexible plastic canula. Rats were held upside-down by the tail for 1-2 minutes to minimize outflow of the dose and were then returned to their cages until recovery. The same procedure was performed with the normal control group but the rats were administered normal saline.

Treatment groups. - Rats were randomized into six groups, each consisting of six animals. Group I (normal control group) received $0.5 \mathrm{~mL}$ oral saline once daily. Group II (colitis control group) received TNBS as mentioned previously and was treated with normal saline similarly to group I. In other four groups, colitis was induced by TNBS and treatments were made orally or rectally $24 \mathrm{~h}$ after induction of colitis with one of the following drugs once daily for 7 days. Group III was administered the BUD optimized formulation ( $300 \mu \mathrm{g} \mathrm{kg}^{-1}$ per day, orally), group IV BUD solution ( $300 \mu \mathrm{g} \mathrm{kg}^{-1}$ per day, orally), group V BUD uncoated pellets ( $300 \mu \mathrm{g} \mathrm{kg}^{-1}$ per day, orally), group VI placebo pellets and group VII animals were treated with BUD enema ( $20 \mu \mathrm{g} \mathrm{kg}^{-1}$ per day, rectally) The pellets were administered to rats via a polyethylene canula (diameter $2 \mathrm{~mm}$ ) with $1 \mathrm{~mL}$ of water.

\section{Assessment of tissue injury}

Clinical signs. - All rats were evaluated twice daily for the presence and severity of diarrhea or rectal bleeding. The rats were also checked daily for their body mass change $(\triangle B M)(\mathrm{g})$. A clinical activity index consisting of scores for three clinical criteria was used to aid the evaluation of colitis (17). The scores were from $0-4$. Severe symptoms were shown by higher grades.

Colon/body mass ratio. - The rats were weighed and euthanized $24 \mathrm{~h}$ after the last dose of drugs. The distal 8-cm portion of the colon of each animal was removed, cut longitudinally and gently washed twice with cold saline solution to clean fecal residues. The colon tissue was weighed after being dried on a filter paper and the colon index (ratio of colon mass to rat body mass, $C / B, \mathrm{mg} \mathrm{g}^{-1}$ ) was used as a parameter to assess the degree of colon edema, which reflected the severity of colon inflammation (18).

Macroscopic damage score. - Macroscopic damage score was calculated according to the criteria reported previously (19). The modified scoring system was: 0 - normal appearance, 1 - erythema and inflammation without ulcer, 2 - inflammation and ulcer, 3 - ulcer with necrosis.

Microscopic evaluation. - After macroscopic evaluation, full thickness biopsy specimens were fixed in $10 \%$ buffered formalin solution, embedded in paraffin, stained with haematoxylin and eosin and them subjected to histopathological studies. Microscopic evaluation was performed by a pathologist unaware of the study design. Histological scoring was carried out as previously described (20). 


\section{Statistical analysis}

The data of drug released at the end of each dissolution test were analyzed using the one-way analysis of variance (ANOVA). The in vivo data were expressed as mean \pm SEM. Differences between the mean values of colon mass/body ratio and ulcer surface area were analyzed using ANOVA followed by Dunnett's post hoc test. Comparison between macroscopic and microscopic damage scores was performed using the Mann-Whitney U-test.

\section{RESULTS AND DISCUSSION}

\section{Influence of core formulation variables on BUD release}

BUD pellet cores were successfully prepared by the extrusion-spheronization method (Table I). Initially, a base formulation was prepared using a combination of Avicel, lactose and BUD. Various concentrations of citric acid were incorporated into the base formulation to achieve the target release profile. The pellets obtained were spherical with satisfactory physical properties. The drug content uniformity was found to be in the range of $98-102 \%$ of BUD in all formulations. The yield range (sieve fraction between $840-1000 \mu \mathrm{m}$ ) was acceptable and between 75 (for F1 formulation) and $68 \%$ (for F4 formulation). The influence of pellet core formulation on the drug release profile was evaluated on pellets subcoated with $\operatorname{HPMC}(6 \%, \mathrm{~m} / \mathrm{m})$ and coated with a Eudragit E layer (LE1).

Fig. 2 compares the budesonide release profiles of designed formulations with different contents of citric acid in PBS ( $\mathrm{pH}$ 6.8). As the results show, the citric acid level in the formulations greatly influenced the drug release. The drug release from pellets was found to be 20 to $32 \%$ for F1 to F3. Increase in citric acid concentration to $20 \%$ (F4) increased the released amount of budesonide statistically $(p<0.05)$ to $47 \%$ but reduced the lag time of release. It seems that acidic functional groups of citric acid lowered the micro-environmental $\mathrm{pH}$ of the pellets and accelerated Eudragit E erosion. However, the controlled-release delivery system for budesonide was not sufficient with only citric acid

Fig. 2. Drug release properties of budesonide pellet cores containing 5,10 , and $20 \%(\mathrm{~m} / \mathrm{m})$ citric acid coated with Eudragit E at $30 \%$ $(m / m)$ coating level (mean $\pm \mathrm{SD}, n=3$ ).

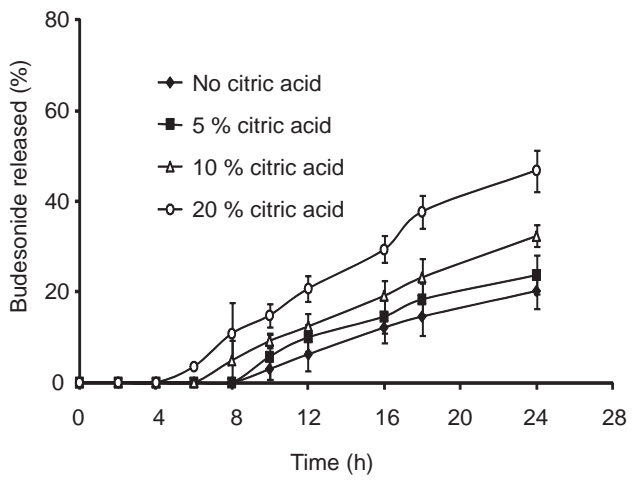


J. Varshosaz et al.: Colon specific delivery of budesonide based on triple coated pellets: In vitro/in vivo evaluation, Acta Pharm. 62 (2012) 341-356.

incorporation in the pellet core. Therefore, the effect of pore formers in Eudragit E was further investigated.

\section{Influence of Eudragit E film composition on budesonide release}

Effect of the concentration and type of pore former. - Based on obtained results, the pellet core formulation containing $20 \%$ citric acid (F4) was selected as optimal for subsequent studies.

To study the effect of pore former level, Eudragit E pellets were coated with 0, 20, 30, 40 and $50 \%$ of HPMC 15000 depending on the mass of Eudragit E (\%, $\mathrm{m} / \mathrm{m})$. It was found that the drug release increased with increasing the level of pore former (Fig. 3a). As the level of pore former increases, the layer becomes more porous after contact with water and faster drug release will happen. At the level of $30 \%(\mathrm{~m} / \mathrm{m})$ of pore former, numbers of pores were sufficient to contribute to significant drug release. However, in the layers that contained 40 and $50 \%(\mathrm{~m} / \mathrm{m})$ of pore former, bursting of the coated pellets was observed during the dissolution run. Since satisfactory drug release was obtained in case of formulations with $30 \%$ pore former, this concentration was selected for further studies.

To study the effect of the type of pore former, sub-coated pellets of BUD were coated with Eudragit E containing different pore formers: HPMC 15000, as a water soluble, water swellable polymer (LE2), lactose 200 as a water soluble, non swellable additive (LE5) and Avicel RC581 as a water insoluble, hydrophilic, water swellable polymer (LE6).

Fig. $3 b$ compares the budesonide release profiles from Eudragit E coated pellets. It is evident that the type of pore former affected drug release and it is possible to achieve the desired release by using different types of pore formers. The poor drug release pattern of lactose may result from the formation of ineffective pores by incomplete leaching of lactose from the film, especially at this high coating level. In the case of HPMC 15000 as pore former, the percentage of drug release was higher due to its higher hydrophilicity than that of lactose. HPMC 15000 could leach out easily and increase the flux rate of the fluid. However, the lag time of drug release was negatively influenced compared to
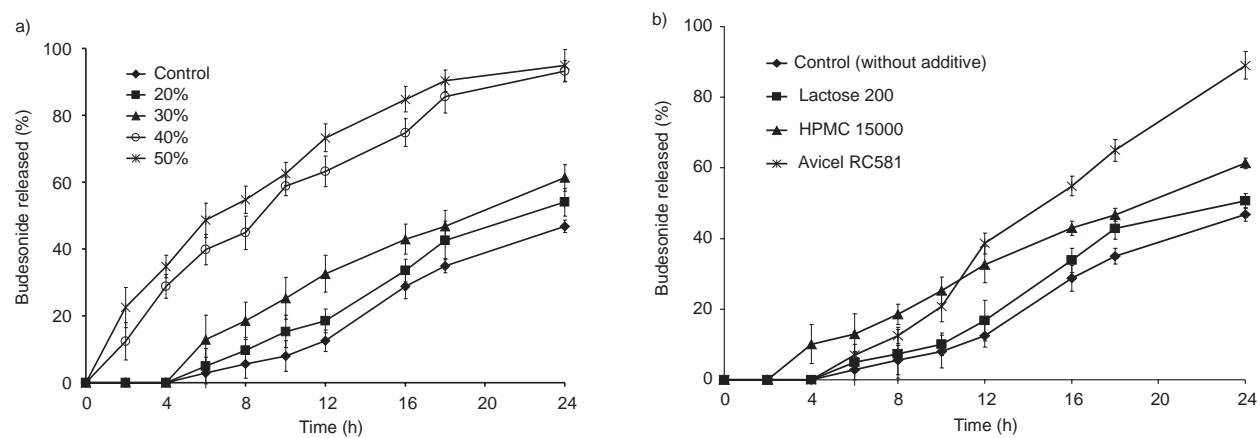

Fig. 3. Effect of: a) the level of pore former and b) the type of pore former on budesonide release from pellets coated with Eudragit E at $30 \%(\mathrm{~m} / \mathrm{m})$ coating level (mean $\pm \mathrm{SD}, n=3$ ). 
the control (4 vs. 6 h). Unexpectedly, Avicel RC581 not only retarded drug release in the simulated environment of small intestine, but it also sustained drug release in the simulated environment of the colon and released most of BUD within $18 \mathrm{~h}$ of the dissolution study in PBS (pH 6.8), so that more than $80 \%$ of drug was released at the end of the dissolution test. To achieve a deeper understanding of the mechanism of enhancement of drug release by Avicel RC581, the dissolution profile of citric acid from the Eudragit E coated pellets containing Avicel RC581 or HPMC 15000 was investigated in comparison with the control. The actual citric acid content of F4 was found to be $19.5 \pm 2.0 \%$ confirming the uniformity of citric acid content in pellet cores.

As shown in Fig. 4, in contrast to HPMC, Avicel RC581 in the Eudragit E film had a marked negative effect on citric acid release. Eudragit $\mathrm{E}$ is insoluble in media with neutral or alkaline $\mathrm{pH}$ and can control the release of highly water soluble components. However, a rapid release profile of citric acid from the pellets was expected due to high water solubility of citric acid allowing quick diffusion. It is thought that Avicel RC581 not only helps Eudragit $\mathrm{E}$ to swell faster due to its fast wetting property but also retards the rapid diffusion out of citric acid, thus maintaining the acidic $\mathrm{pH}$ inside the pellets for a longer period of time. In other words, as the dissolution medium enters the core of the pellets, citric acid dissolves rapidly, releases slowly on the surface of Eudragit E film and helps the erosion of the film, which in turn enhances the release of BUD. Avicel RC 581 is a co-processed excipient consisting of a microcrystalline cellulose (MCC) and sodium carboxymethyl cellulose $(\mathrm{NaCMC})$ blend. It seems that $\mathrm{NaCMC}$ had the most significant impact on Eudragit E hydration and MCC caused increased resistance to citric acid release.

Effect of enteric film coatings. - To protect both Eudragit $\mathrm{E}$ and the drug from the effects of acidic $\mathrm{pH}$ of the stomach, the optimized two-layered coated pellets were subsequently coated with aqueous HPMC AS at different coating levels to obtain the complete enteric coated pellets. The results of the study of BUD release from enteric coated pellets that were subjected to $0.1 \mathrm{~mol} \mathrm{~L}^{-1} \mathrm{HCl}$ for $2 \mathrm{~h}$ showed no drug release in the coating range of 12 to $20 \%, \mathrm{~m} / \mathrm{m}$ (results not shown).

Fig. 4. Effect of the type of pore former on citric acid release from pellets coated with Eudragit E at $30 \%(\mathrm{~m} / \mathrm{m})$ coating level (mean \pm $\mathrm{SD}, n=3)$.

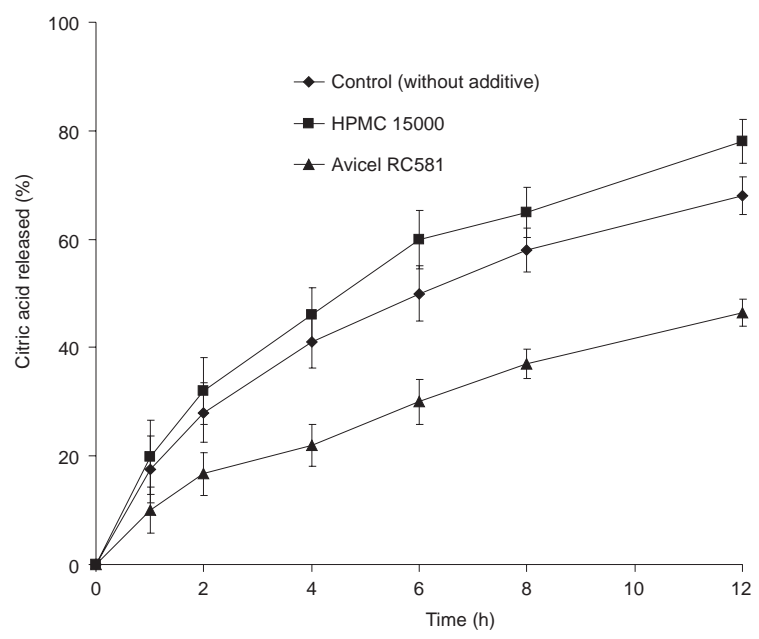


Based on the results obtained, the best formulation consisting of $20 \%$ citric acid in the core, coated with Eudragit E containing Avicel RC581 as pore former, was selected based on its in vitro characteristics and was used for in vivo studies.

\section{Accelerated stability study}

Fig. 5 shows the release profiles of the optimum formulation at zero time and during storage. No significant difference was found between the drug release profiles of the stored samples after three-month storage under accelerated conditions and $f_{2}$ was more than 50 compared to this value for the control samples. There were no signs of visually distinguishable changes in appearance and color of pellets. The drug content was comparable with that of the control samples and within acceptable limits. On the basis of these results, it can be concluded that the formulation had enough stability under the accelerated stability test conditions for three months.

\section{Reproducibility study}

Reproducibility of the coating procedures was confirmed by preparing three repeated batches of the optimized formulation on three different occasions. Release studies were conducted according to the procedure described earlier and similar release profiles were obtained from all three batches (results not shown), demonstrating that the designed formulation produced reproducible release results. The $f_{2}$ values were found to be 84 (between batches 1 and 2), and 80 (between batches 1 and 3), and 82 (between batches 2 and 3$)$.

\section{Kinetic modeling of drug release}

The results of kinetic models fitted to budesonide release from the optimized formulation are shown as the release constant $(k)$ and the coefficient of determination $\left(R^{2}\right)$

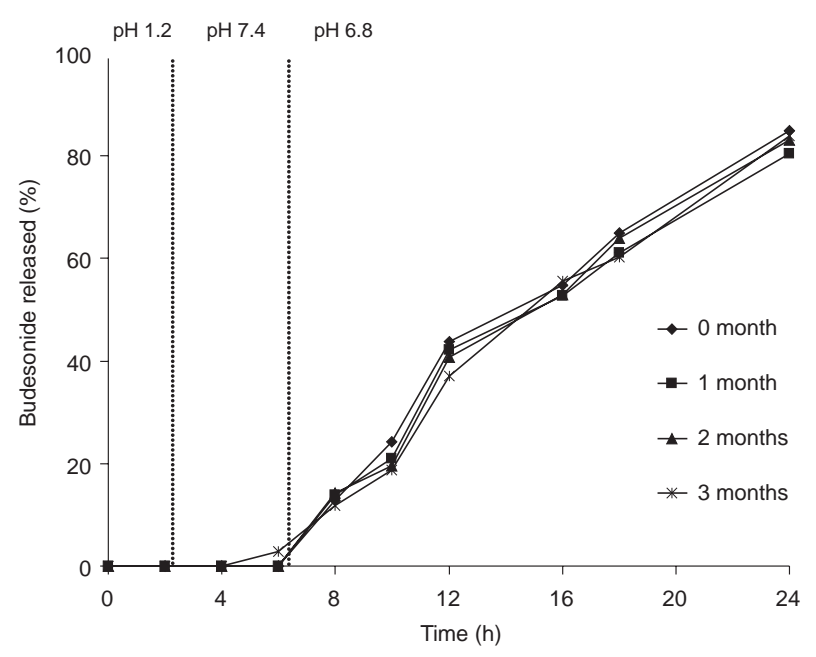

Fig. 5. In vitro dissolution profiles of multi-layer film coated pellets at zero time and after storage at $40{ }^{\circ} \mathrm{C} / 75 \% \mathrm{RH}$ for 1,2 and 3 months. 
J. Varshosaz et al.: Colon specific delivery of budesonide based on triple coated pellets: In vitro/in vivo evaluation, Acta Pharm. 62 (2012) 341-356.

Table IV. Release kinetic values of optimized multilayer coated pellets of budesonide

\begin{tabular}{cccccccc}
\hline \multicolumn{2}{c}{ Zero-order } & \multicolumn{2}{c}{ First-order } & \multicolumn{2}{c}{ Higuchi } & \multicolumn{2}{c}{ Hixson-Crowell } \\
\hline$R^{2}$ & $K_{\mathrm{o}}\left(\% \mathrm{~h}^{-1}\right)$ & $R^{2}$ & $k_{1}\left(\mathrm{~h}^{-1}\right)$ & $R^{2}$ & $k_{\mathrm{H}}\left(\% \mathrm{~h}^{-1 / 2}\right)$ & $R^{2}$ & $k_{\mathrm{HC}}(\%)^{1 / 3} \mathrm{~h}^{-1}$ \\
0.9714 & 4.9862 & 0.9523 & -38.179 & 0.9541 & 38.132 & 0.987 & 1.6097 \\
\hline
\end{tabular}

in Table IV. The results revealed that the drug release was best supported by zero-order release $\left(R^{2}=0.9714\right)$, which indicated that the rate of drug release was controlled by surface erosion rather than drug diffusion. The release profile of BUD displayed fairly good fitting with the Hixson-Crowell cube root model of drug release, confirming that the drug was released by dissolution and with the changes in surface area and diffusion path length during the dissolution process.

\section{In vivo studies}

Clinical activity score. - All rats in the normal control group had normal activity during all phases of the study while, as expected, all animals treated with TNBS developed clinical symptoms such as loss of appetite, bloody diarrhea and significant body mass loss $(p<0.001)$, which provided confirmation of the colitis model. On day 0 , the body mass of rats was $180.0 \pm 8.3 \mathrm{~g}$ in the healthy control group $(n=6)$ and $182.5 \pm 12.7 \mathrm{~g}$ in the groups treated with TNBS $(n=48)$, which shows no significant difference between them. The average mass gain in the healthy control group was $15.7 \pm 0.9 \%$, but the rats in the colitis group suffered significant body mass loss $18.6 \pm 2.7 \%)(p<0.05)$. The results in Table V show that, except for placebo pellets (group VI) that do not show a significant difference from the colits control group (group II), all other groups differ in the body mass changes from the colitis control group significantly $(p<0.05)$. Treatment with

Table V. Clinical and macroscopic evaluation of colitis in different groups of rats after a 7-day treatment

\begin{tabular}{ccccc}
\hline $\begin{array}{c}\text { Treatment } \\
\text { group }\end{array}$ & $\begin{array}{c}\text { Body mass } \\
\text { change }(\%)\end{array}$ & $\begin{array}{c}\text { Clinical activity } \\
\text { score }\end{array}$ & $\begin{array}{c}C / B \\
\left(\mathrm{mg} \mathrm{g}^{-1}\right)\end{array}$ & $\begin{array}{c}\text { Macroscopic } \\
\text { score }\end{array}$ \\
\hline I & $15.7 \pm 0.9$ & $0.0 \pm 0.0$ & $2.5 \pm 0.7$ & $0.0 \pm 0.0$ \\
II & $-18.6 \pm 2.7$ & $4.5 \pm 0.2$ & $12.9 \pm 0.7$ & $3.0 \pm 0$ \\
III & $4.4 \pm 1.7$ & $1.5 \pm 0.3$ & $7.2 \pm 0.5$ & $2.2 \pm 0.3$ \\
IV & $1.9 \pm 1.5$ & $2.1 \pm 0.2$ & $9.1 \pm 0.2$ & $2.7 \pm 0.2$ \\
V & $-3.2 \pm 1.3$ & $1.9 \pm 0.5$ & $9.0 \pm 0.3$ & $2.7 \pm 0.3$ \\
VI & $-15.9 \pm 2.6$ & $4.3 \pm 0.6$ & $11.4 \pm 0.6$ & $2.8 \pm 0.4$ \\
VII & $9.9 \pm 0.9$ & $2.2 \pm 0.3$ & $4.7 \pm 0.4$ & $2.1 \pm 0.4$ \\
\hline
\end{tabular}

I - normal control, II - colitis control, III - budesonide coated pellets (300 $\mu \mathrm{g} \mathrm{kg}^{-1}$ day $\left.^{-1}\right)$, IV - budesonide solution $\left(300 \mu \mathrm{g} \mathrm{kg}^{-1} \mathrm{day}^{-1}\right), \mathrm{V}$ - budesonide uncoated pellets $\left(300 \mu \mathrm{g} \mathrm{kg}^{-1}\right.$ day $\left.^{-1}\right), \mathrm{VI}-$ placebo pellets, VII - budesonide enema ( $20 \mu \mathrm{g} \mathrm{kg}^{-1}$ day $^{-1}$, rectally).

The results are expressed as arithmetic mean \pm SEM, $n=6$.

$C / B-$ colon to body mass ratio. 


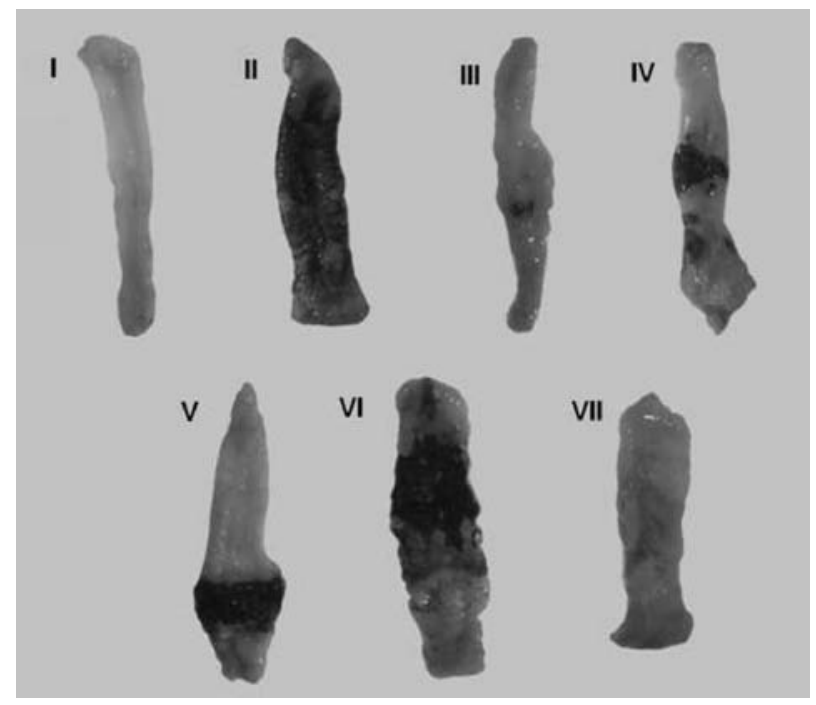

Fig. 6. Representative macroscopic appearance of rat colonic mucosa: I - normal control, II - colitis control, III - budesonide coated pellets $\left(300 \mu \mathrm{g} \mathrm{kg}^{-1}\right.$ day $\left.^{-1}\right)$ improved TNBS-induced colitis and decreased the ulcer surface, IV - budesonide solution $\left(300 \mu \mathrm{g} \mathrm{kg}^{-1}\right.$ day $\left.^{-1}\right), \mathrm{V}$ - budesonide uncoated pellets $\left(300 \mu \mathrm{g} \mathrm{kg}^{-1} \mathrm{day}^{-1}\right), \mathrm{VI}$ - placebo pellets, VII - budesonide enema $\left(20 \mu \mathrm{g} \mathrm{kg}^{-1}\right.$ day $^{-1}$, rectally).

BUD coated pellets coused significant body mass gain of $4.4 \pm 1.7 \%$. During the treatment period, the signs of colitis started to decrease in severity for all treated groups (except the placebo treated group). The BUD coated pellets and BUD enema showed statis-

Table VI. Histological evaluation of colitis in different groups of rats following a 7-day treatment

\begin{tabular}{ccccc}
\hline \multirow{2}{*}{$\begin{array}{c}\text { Treatment } \\
\text { group }\end{array}$} & $\begin{array}{c}\text { Inflammation } \\
\text { severity }\end{array}$ & $\begin{array}{c}\text { Inflammation } \\
\text { extent }\end{array}$ & $\begin{array}{c}\text { Crypt } \\
\text { damage }\end{array}$ & $\begin{array}{c}\text { Total histological } \\
\text { score }\end{array}$ \\
\cline { 2 - 5 } I & 0 & 0 & 0 & 0 \\
II & $2.8 \pm 0.1$ & $2.8 \pm 0.1$ & $3.3 \pm 0.5$ & $8.1 \pm 1.3$ \\
III & $2.2 \pm 0.3$ & $2.3 \pm 0.3$ & $1.8 \pm 0.6$ & $6.3 \pm 0.8$ \\
IV & $2.3 \pm 0.3$ & $2.2 \pm 0.4$ & $3.7 \pm 0.3$ & $7.6 \pm 0.9$ \\
V & $2.5 \pm 0.2$ & $2.2 \pm 0.3$ & $2.8 \pm 0.8$ & $7.0 \pm 1.0$ \\
VI & $2.7 \pm 0.2$ & $2.7 \pm 0.4$ & $3.0 \pm 0.8$ & $7.6 \pm 0.7$ \\
VII & $3.0 \pm 0.9$ & $2.5 \pm 0.2$ & $2.6 \pm 1.1$ & $6.9 \pm 0.5$ \\
\hline
\end{tabular}

I - normal control, II - colitis control, III - budesonide coated pellets $\left(300 \mu \mathrm{g} \mathrm{kg}^{-1} \mathrm{day}^{-1}\right)$, IV - budesonide solution $\left(300 \mu \mathrm{g} \mathrm{kg}^{-1} \mathrm{day}^{-1}\right), \mathrm{V}$ - budesonide uncoated pellets $\left(300 \mu \mathrm{g} \mathrm{kg}^{-1}\right.$ day $\left.^{-1}\right), \mathrm{VI}-$ placebo pellets, VII - budesonide enema ( $20 \mu \mathrm{g} \mathrm{kg}^{-1}$ day $^{-1}$, rectally).

a All values are reported as mean \pm SEM, $n=6$. 

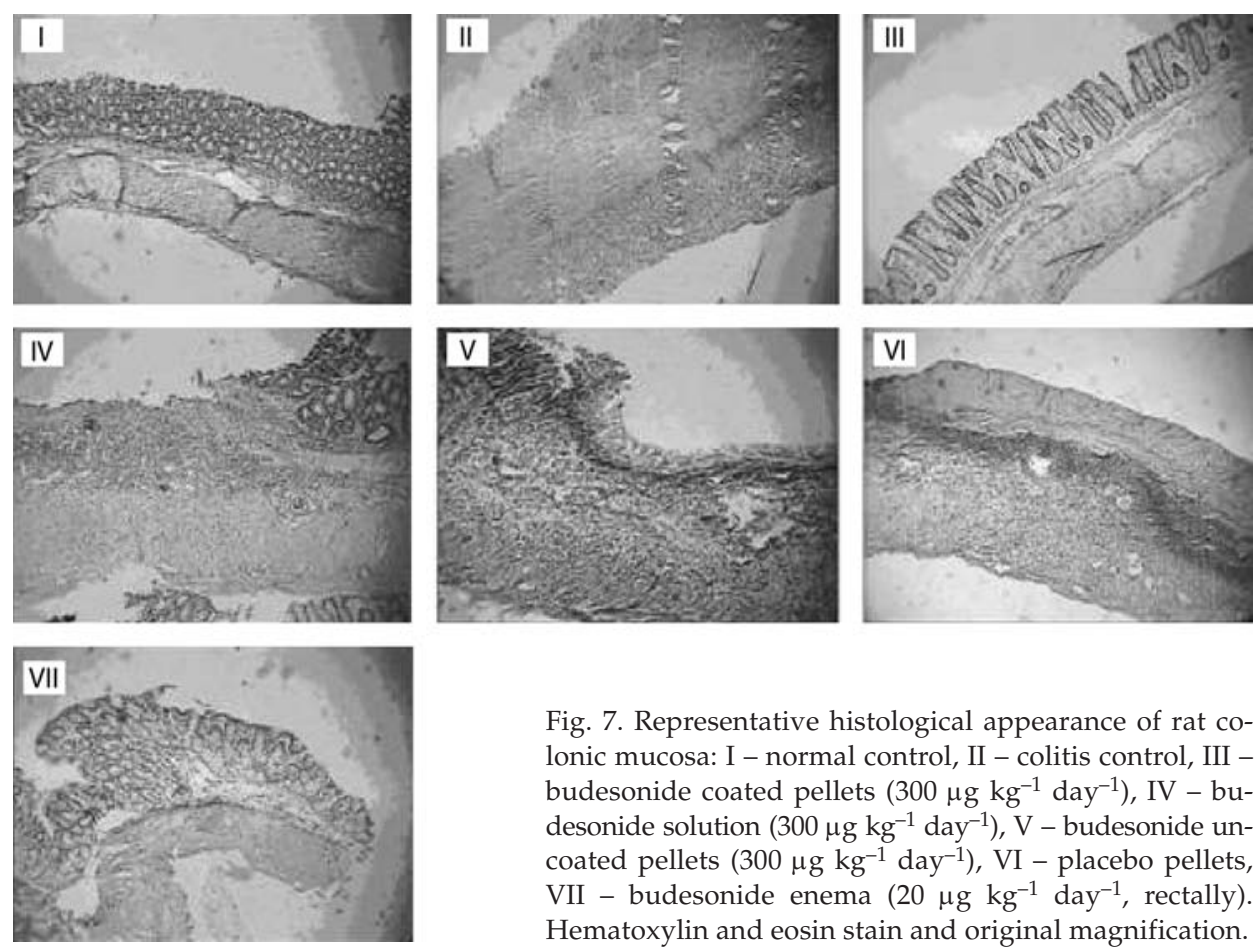

Fig. 7. Representative histological appearance of rat colonic mucosa: I - normal control, II - colitis control, III budesonide coated pellets $\left(300 \mu \mathrm{g} \mathrm{kg}^{-1}\right.$ day $\left.^{-1}\right), \mathrm{IV}-\mathrm{bu}-$ desonide solution $\left(300 \mu \mathrm{g} \mathrm{kg}^{-1}\right.$ day $\left.^{-1}\right), \mathrm{V}$ - budesonide uncoated pellets $\left(300 \mu \mathrm{g} \mathrm{kg}^{-1} \mathrm{day}^{-1}\right), \mathrm{VI}-$ placebo pellets, VII - budesonide enema $\left(20 \mu \mathrm{g} \mathrm{kg}^{-1}\right.$ day $^{-1}$, rectally). Hematoxylin and eosin stain and original magnification.

tically different results from the colitis group, while there was no statistical difference between the BUD solution and BUD uncoated pellets-treated groups.

Colon/body mass ratio. - The $C / B$ ratio after intracolonic administration of TNBS was significantly higher compared to the healthy control group $(p<0.05)$. After oral administration of BUD solution or uncoated BUD pellets the $C / B$ ratio was decreased compared to the colitis group, however not significantly. A better therapeutic effect was observed after administration of coated BUD pellets compared to BUD solution and BUD uncoated pellets $(p<0.05)$ due to the fact that the new formulation prevented immediate drug release in the small intestine and most of BUD was released throughout the entire colon. Nevertheless, the seven-day administration of the new formulation could not reduce the $C / B$ ratio to a level comparable to $B U D$ enema. Table $V$ shows the data of the $C / B$ ratio obtained in rats after the treatment.

Macroscopic damage score and histopathological studies. - Fig. 6 I shows normal colon with no damage in macroscopic examination, but the colon in colitis control group was severely damaged, showing mucosal hyperaemia, hemorrhage, deep ulcers and necrosis (Fig. 6 II). Daily treatment with BUD coated pellets for 7 days attenuated the macroscopic damage scores significantly compared to the colitis control group and groups treated with BUD solution and BUD uncoated pellets $(p<0.05)$ but was comparable to BUD enema (Table V). 
Fig. 7 I shows the histology of normal colon. It is evident from Fig. 7 II that colitis colon showed extensive necrotic destruction of the epithelium, hemorrhage, edema, crypt damage and ulceration at mucosal and sub-mucosal layers, in addition to inflammatory cellular infiltration. In the rats treated with BUD solution and BUD uncoated pellets, cellular infiltration as well as broken epithelial lining were evident (Figs. 7 IV and V), suggesting inadequate effectiveness of BUD solution and uncoated pellets in rectifying the colitis induced by TNBS administration. However, the histopathological features of the colon clearly indicated that the morphological disturbances associated with TNBS administration were attenuated after seven days of oral administration of BUD coated pellets and rectal administration of BUD enema (Figs. 7 III and VII). Table VI shows the means of colon tissue histological parameters colon tissue for each group.

The results of the in vivo study allow the conclusion that the studied formulation showed colon specificity in delivering the drug to the colon and prevention of premature release in upper parts of GIT. Indeed, the optimized formulation (pellets containing citric acid $20 \%, \mathrm{~m} / \mathrm{m}$, coated with $6 \%, \mathrm{~m} / \mathrm{m}$ HPMC, Eudragit E at coating level of $30 \%$, $\mathrm{m} / \mathrm{m}$ which contained $30 \%$ of Avicel RC 581 as pore former and finally coated with $15 \%$, $m / m$ HPMC AS) was superior to BUD solution and uncoated pellets, which were readily absorbed from the intestine and after very high first pass metabolism, a small amount of the drug was delivered to the colon.

\section{CONCLUSIONS}

In the present study, a multiparticulate system for colonic delivery of BUD was developed. The designed system was highly promising for potential targeting of budesonide to the lower intestinal tract with no release under simulated gastric and small intestinal conditions and sustained release after a controllable lag time in simulated colonic media. The release pattern was independent of the environmental medium and the mobility of the GIT. Besides, the in vivo performance of the optimized formulation was confirmed using a trinitrobenzenesulfonic acid (TNBS)-induced colitis model in rat. Although the formulation is moderately complex, its manufacture is simple and reproducible, and could be easily manufactured on a large scale in a reasonable processing time using standard pharmaceutical equipment. In vivo study in the induced UC rats showed that oral administration of new BUD coated pellets exerted a favorable impact on the colonic ulcer healing by decreasing the area of colonic ulcerations, reducing the mass of the colon and improving the symptoms of colitis. However, human studies are needed to investigate its potential effect by conducting scintigraphic studies.

\section{REFERENCES}

1. D. C. Baumgart, Treatment of inflammatory bowel disease: A review of medical therapy, World J. Gastroenterol. 21 (2008) 354-377; DOI: 10.3748/wjg.14.354.

2. U. Klotz and M. Schwab, Topical delivery of therapeutic agents in the treatment of inflammatory bowel disease, Adv. Drug Deliv. Rev. 57 (2005) 267-279; DOI: 10.1016/j.addr.2006.09.011. 
3. M. Jiménez and A. S. Peña, Budesonide for ulcerative colitis, Rev. Esp. Enferm. Dig. 98 (2006) 362-373; DOI: 1130-0108/2006/98/5/362-373.

4. K. Dilger, M. Alberer, A. Busch, A. Enninger, R. Behrens, S. Koletzko, M. Stern, C. Beckmann and C. H. Gleiter, Pharmacokinetics and pharmacodynamic action of budesonide in children with Crohn's disease, Aliment. Pharmacol. Ther. 23 (2006) 387-395; DOI: 10.1111/j.1365-2036.2006. 02771.x.

5. J. Seidegård, L. Nyberg and O. Borgå, Presystemic elimination of budesonide in man when administered locally at different levels in the gut, with and without local inhibition by ketoconazole, Eur. J. Pharm. Sci. 15 (2008) 264-70; DOI: 10.1016/j.ejps.2008.07.005.

6. L. F. Asghar and S. Chandran, Multiparticulate formulation approach to colon specific drug delivery: current perspectives, J. Pharm. Pharm. Sci. 9 (2006) 327-338.

7. Y. Krishnamachari, P. Madan and S. Lin, Development of pH- and time-dependent oral microparticles to optimize budesonide delivery to ileum and colon, Int. J. Pharm. 29 (2007) 238-47; DOI: 10.1016/j.ijpharm.2007.02.015.

8. A. Makhlof, Y. Tozuka and H. Takeuchi, pH-Sensitive nanospheres for colon-specific drug delivery in experimentally induced colitis rat model, Eur. J. Pharm. Biopharm. 72 (2009) 1-8; DOI: 10.1016/j.ejpb.2008.12.013.

9. United States Pharmacopoeia 32, National Formulary 29, USP Convention, Rockville 2002.

10. J. Varshosaz, J. Emami, N. Tavakoli, A. Fassihi, M. Minaiyan, F. Ahmadi and F. Dorkoosh, Synthesis and evaluation of dextran-budesonide conjugates as colon specific prodrugs for treatment of ulcerative colitis, Int. J. Pharm. 365 (2009) 69-76; DOI: 10.1016/j.ijpharm.2008.08.034.

11. J. Ding, X. Wang, T. Zhang, Q. Li and M. Luo, Optimization of RP-HPLC analysis of low molecular weight organic acids in soil, J. Liq. Chrom. Rel. Tech. 29 (2006) 99-111; DOI: 10.1080/ 10826070500363050.

12. T. Higuchi, Mechanism of sustained-action medication, J. Pharm. Sci. 52 (1963) 1145-1149; DOI: 10.1002/jps. 2600521210.

13. R. W. Korsmeyer, R. Gurny, E. Doelker, P. Buri and N. A. Peppas, Mechanisms of solute release from porous hydrophilic polymers, Int. J. Pharm. 15 (1983) 25-35; DOI: 10.1016/0378-5173(83) 90064-9.

14. N. A. Peppas, Analysis of Fickian and non-Fickian drug release from polymers, Pharm. Acta Helv. 60 (1985) 110-111.

15. P. Costa and J. M. Sonsa Lobo, Modelling and comparison of dissolution profiles, Eur. J. Pharm. Sci. 13 (2001) 123-133; DOI: 10.1016/S0928-0987(01)00095-1.

16. G. P. Morris, P. L. Beck, M. S. Herridge, W. T. Depew, M. R. Szewczuk and J. L. Wallace, Hapten-induced model of colonic inflammation and ulceration in the rat colon, Gastroenterology 96 (1989) 795-803.

17. S. Choudhary, A. Keshavarzian, S. Yong, M. Wade, S. Bocckino, B. J. Day and A. Banan, Novel antioxidants zolimid and AEOL11201 ameliorate colitis in rats, Dig. Dis. Sci. 46 (2001) 2222-2230; DOI: $10.1023 /$ A: 1011975218006.

18. S. Y. Zhou, Q. B. Mei, L. Liu, X. Guo, B. S. Qiu, D. H. Zhao and C. H. Cho, Delivery of glucocorticoid conjugates in rat gastrointestinal tract and its treatment for ulcerative colitis, Acta Pharmacol. Sin. 22 (2001) 761-764.

19. J. L. Wallace and C. M. Keenan, An orally active inhibitor of leukotriene synthesis accelerates healing in a rat model of colitis, Am. J. Physiol. 258 (1990) 527-534.

20. C. B. Appleyard and J. L. Wallace, Reactivation of hapten-induced colitis and its prevention by anti-inflammatory drugs, Am. J. Physiol. 269 (1995) 119-125. 
J. Varshosaz et al.: Colon specific delivery of budesonide based on triple coated pellets: In vitro/in vivo evaluation, Acta Pharm. 62 (2012) 341-356.

$S A \check{Z} E T A K$

\section{Ciljana isporuka budezonida u kolonu iz trostruko obloženih peleta: In vitro/in vivo evaluacija}

JALEH VARSHOSAZ, JABER EMAMI, NASER TAVAKOLI, MOHSEN MINAIYAN, NAKISA RAHMANI, FARID DORKOOSH i PARVIN MAHZOUNI

U radu je opisana priprava troslojnih peleta budezonida za ciljanu isporuku u kolonu metodom ekstruzije-sferonizacije. Obložni slojevi sastojali su se od hidroksipropilmetilceluloze (HPMC) (barijerni sloj), Eudragita E (kontrolni sloj) i hidroksipropilmetilceluloze acetat sukcinata (HPMC AS) (želučanootporni sloj). Sloj koji kontrolira oslobađanje je dalje modificiran koristeći različite tvari koje stvaraju pore. Oslobađanje je proučavano pri pH 1,2, 7,4 i 6,8. Sastav jezgre pelete, te vrsta i količina tvari koje stvaraju pore utjecale su na oslobađanje lijeka iz peleta. Pelete koje u jezgri sadrže $20 \%(\mathrm{~m} / \mathrm{m})$ limunske kiseline obložene s HPMC (6\%, $m / m)$, Eudragit E s Avicelom RC 581 kao tvari za stvaranje pora $(30 \%, \mathrm{~m} / \mathrm{m})$ i HPMC AS $(15 \%, \mathrm{~m} / \mathrm{m})$ imale su najbolji profil oslobađanja. Pelete su pokazale dobre rezultate $\mathrm{u}$ eksperimentalnom modelu kolitisa $\mathrm{u}$ štakora induciranog trinitrobenzensulfonskom kiselinom.

Ključne riječi: isporuka u kolonu, troslojne pelete, Eudragit E, budezonid, HPMC AS, HPMC

Department of Pharmaceutics, Faculty of Pharmacy and Novel Drug Delivery Systems Research Center Isfahan University of Medical Sciences, Isfahan, Iran

Department of Pharmacology, Faculty of Pharmacy and Isfahan Pharmaceutical Sciences Research Center Isfahan University of Medical Sciences, Isfahan, Iran

Department of Pharmaceutics, Faculty of Pharmacy, Tehran University of Medical Sciences, Tehran, Iran Department of Clinical Pathology, Faculty of Medicine, Isfahan University of Medical Sciences, Isfahan Iran 